Results Ultrasound measurement of SPD was equal to Touhy needle in 23/30 (76.7\%), while overestimated in $1 / 30(3.3 \%)$ by $0.2 \mathrm{~cm}$ and underestimated in $6 / 30(20 \%)$ by a mean of $0.5 \mathrm{~cm}$. BMI measurement of SPD was equal to Touhy needle in $0 / 30(0 \%)$, while overestimated in $25 / 30(83.3 \%)$ by a mean of $1.14 \mathrm{~cm}$ and underestimated in $5 / 30(16.7 \%)$ by a mean of $0.29 \mathrm{~cm}$. Ultrasound was more accurate than BMI in the measurement of SPD based on Wilcoxon signed-rank test (non-parametric) with a p-value $<0.00001$.

Conclusions Compared to BMI, ultrasound offers more accurate measurement of SPD.

\section{POST-CESAREAN SECTION ANALGESIA WITH QUADRATUS LUMBORUM BLOCK 5 IN A PUERPERAL WOMAN: A CASE REPORT}

L Vieira, B Alves* , CR Almeida. Centro Hospitalar Tondela Viseu, Viseu, Portugal

10.1136/rapm-2021-ESRA.108

Background and Aims A 42-year-old pregnant woman refused neuroaxial anaesthesia for a scheduled cesarean section (c-section), therefore a balanced general anaesthesia was performed. The c-section was uneventful. Before extubation, in a supine position, an ultrasound guided lumbar bilateral quadratus lumborum block (QLB) 5 was performed with a single shot dose of $20 \mathrm{ml}$, per side, of ropivacaine $0,5 \%$. During the first 24 hours post-operative, the patient remained comfortable, with paracetamol $1 \mathrm{~g}$ every 8 hours, intravenously, without other analgesic medication.

Methods Different variations of QLB have been performed for analgesia after c-section, but Transmuscular QLB (T-QLB) is frequently chosen, due to long lasting duration and to better visceral analgesia, but the patient must be positioned in both lateral position alternately.

Results Recently Almeida et al, ${ }^{2}$ described the QLB5 and the LAlat Block, the latter not for abdominal pain, using the same sonoanatomy of the T-QLB, but maintaining the supine position. The anesthetic is injected from anterior/lateral to posterior/medial direction between the psoas major muscle (PMM)

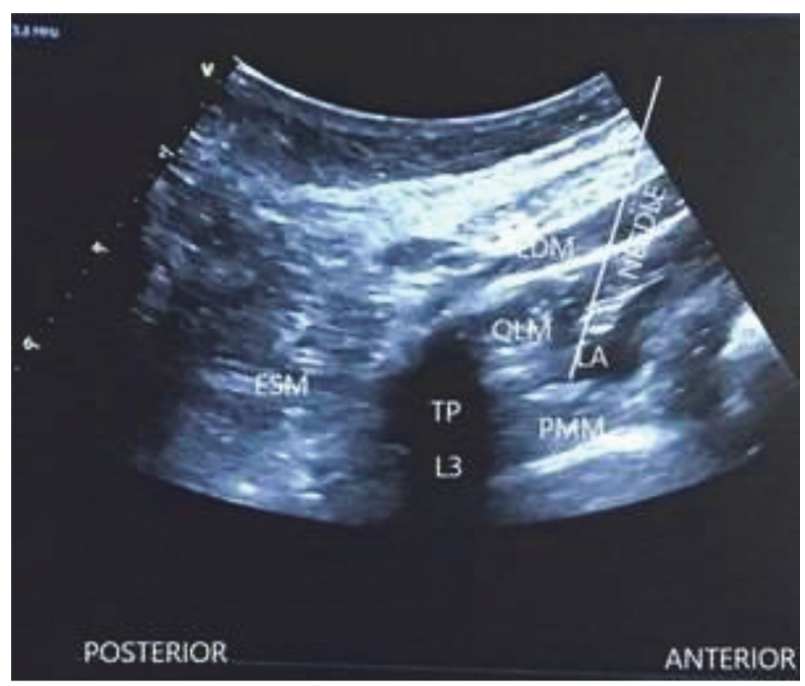

Abstract 108 Figure 1 Ultrasound image showing performance of a modified anterior QLB, a novel QLB 5. ESM, Erector spinae muscle; LA, Local anaesthetic. and the quadratus lumborum muscle (QLM) (figure 1). The insertion point at QLB5 is anterior to the probe. This approach (QLB5) provides similar dispersion as the T-QLB; the gravid uterus or other abdominal structure are easily avoided as with the T-QLB; this happens because QLM functions as a safe path for the needle.

Conclusions The QLB5 is safe and allows prolonged abdominal (somatic and visceral) analgesia for post-c-section.

\section{AN AUDIT OF RESPONSE TIMES TO EPIDURAL REQUESTS ON A BUSY UK LABOUR WARD}

T Moody*, A Qureshi, M Nejdlova. University Hospital Birmingham, Birmingham, UK

\subsection{6/rapm-2021-ESRA.109}

Background and Aims Epidural analgesia is the gold standard for labour analgesia. Recently the availability and timing of an epidural has been topical in the UK news ${ }^{3,4,5}$. The time from an anaesthetist being informed of epidural request to attendance should be less than 30 minutes; or 60 in exceptional circumstances. This single centre audit aims to assess anaesthetic attendance times according to the standards set by the OAA and AAGBI ${ }^{1,2}$.

Methods We looked at all epidural requests over 3 months at a busy UK maternity unit. With each epidural, the time of request, the time of anaesthetist being informed and the time of attendance of anaesthetist were noted. Reasons for delays, including delays between the request and informing the anaesthetist were recorded.

Results 31 from 50 epidural requests had the anaesthetist attend within 30 minutes of being informed. The anaesthetist attended 37 times within 60 minutes of being informed.

The most common reasons for delay were unavailability of the anaesthetist, the anaesthetist not being informed, CTG concerns and awaiting blood results.

Conclusions Out of hours, one resident anaesthetist was on call with a non-resident consultant. If a case was on-going in theatre, this potentially delayed discussion for epidural. It highlights the need for additional resident labour ward anaesthetists at busy units in line with GPAS guidelines ${ }^{1}$. In our unit we rolled out an educational program aimed at educating

\section{Abstract 109 Table 1}

\begin{tabular}{|c|c|}
\hline 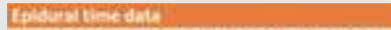 & 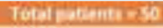 \\
\hline $\begin{array}{l}\text { Ansesthetivt attending within } \mathbf{3 0} \text { minutes of } \\
\text { being informed }\end{array}$ & $31 / 50$ \\
\hline $\begin{array}{l}\text { Ansesthetist attending within } 60 \text { minutes of } \\
\text { being informed }\end{array}$ & $37 / 50$ \\
\hline $\begin{array}{l}\text { Ansesthetist attending withis } 30 \text { minutes of } \\
\text { initial respest }\end{array}$ & $27 / 50$ \\
\hline Resson for delay documented in patient notes & $25 / 50$ \\
\hline
\end{tabular}

Abstract 109 Table 2

\begin{tabular}{|c|c|}
\hline 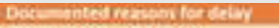 & Tetur documested realons tor desy o is \\
\hline Ansesthetist unuvalable & 10 \\
\hline Ansesthetist not informed & 7 \\
\hline CTO conteens & 5 \\
\hline Blood rewelts unavailable & s \\
\hline Lack of trained midwite & 3 \\
\hline Delivery is likely imminent & 2 \\
\hline Datient awaiting obstetrix review & 1 \\
\hline Eevipment iswes & 1 \\
\hline Awaining viterotonirs to start & 1 \\
\hline
\end{tabular}

